\title{
LA SENTENCIA MÁS LARGA Repercusiones de la STC 21/2010: política y jurisprudencia
}

\author{
JUAN F. LÓPEZ AGUILAR ${ }^{1}$ \\ Catedrático de Derecho Constitucional \\ Universidad de Las Palmas de Gran Canaria
}

\begin{abstract}
SUMARIO
0 Premisas

I Los contenidos esenciales de la sentencia del TC sobre el recurso contra el Estatut de Cataluña interpuesto por más de 50 diputados del GP popular en el congreso

II Comentarios sobre su impacto en la doctrina del TC en la interpretación y manejo del bloque de constitucionalidad

III Comentarios sobre su impacto en el entorno político institucional del estado autonómico

IV Conclusiones: un comentario sobre el TC, su crisis y perspectivas de futuro
\end{abstract}

\section{PREMISAS}

La Constitución Española de 1978 acaba de celebrar su XXXII aniversario. La largura de la efeméride impresiona. Esta es la Constitución a la que tantos profesores y estudiosos del Derecho hemos dedicado buena parte de nuestras vidas; no sólo de nuestra actividad profesional, que por descontado así ha sido, sino también de la encuadrada en la creatividad intelectual, el compromiso cívico e incluso, en no pocos casos, la incursión en la política.

En perspectiva histórica, esta es la Constitución que más prolongada vigencia y profundidad de desarrollo se ha conocido en España, incluso si la comparamos, y lo hacemos en serio, con la Constitución de la Restauración de 1876. Desde el punto de vista doc-

1 Presidente de la Comisión de Libertades, Justicia y Asuntos de Interior del Parlamento Europeo. 
trinal, nunca antes en España había conocido la ciencia del Derecho una floración tan importante como la experimentada a partir de la entrada en vigor de esta Norma fundamental, cualitativamente más afortunada que ninguna de las precedentes tanto por su legitimación democrática como por sus avanzadas soluciones normativas, su despliegue y su arraigo.

En lo personal, hace ya tiempo que me he distanciado de cualquier tentación de sostener toda inercia que propendiese a prolongar la adjetivación de nuestra democracia como «joven», un piadoso subterfugio para encubrir otros calificativos menos halagüeños tales como los de «inexperta», «inmadura» o «frágil». La nuestra es ya, definitivamente, y de una vez por todas, una Constitución madura, sólida y solidificada por el paso del tiempo; funda una democracia estable y resistente a la crítica, imperfecta como todas, pero comparable a las más prestigiosas de la tierra.

Buena parte del prestigio y éxito de la Constitución se ha construido a partir de las actuaciones del Tribunal Constitucional. «Intérprete supremo»—que no único- de la Constitución (art.1.1 LOTC), el TC ha venido siendo durante décadas fuente preferencial de inspiración de la doctrina y de los comentaristas de la vida constitucional. Tan alta preponderancia del TC se puso de manifiesto desde la más temprana fase del desarrollo constitucional. Tanto es así, que la Constitución pronto pasó a ser conocida como «jurisdiccionalizada»; y todos y cada uno de sus capítulos — derechos y libertades, forma de gobierno, apertura a la UE y al exterior, estructura territorial de la diversidad en la unidad- pasaron a ser tratados, resueltos y comprensibles sólo desde el tamiz de la jurisdicción constitucional del TC.

En particular, el Estado Autonómico fue denominado tempranamente «Estado jurisprudencial autonómico» ${ }^{2}$, casi a partir de la misma definición de la autonomía como concepto distinto del de soberanía. (STC 4/81): La delimitación del orden competencial, la caracterización constitucional del sistema de fuentes del Derecho - los principios de jerarquía, competencia y función constitucional; el par bases/desarrollo, la norma de conflicto y Derecho supletorio, la incardinación del principio de autonomía local en la arquitectura territorial del Estado- . Todo el orden constitucional ha sido en buena medida elaborado y reelaborado por el TC, y sólo a partir del TC nos hemos dispuesto explicarlo los profesores de Derecho, partiendo de los principios y las elaboraciones dictadas por el TC 3 .

Y sin embargo, nunca una sola sentencia había sido tan esperada, tan comentada y tan ampliamente asumida como una sentencia decisiva. Tal ha sido el caso de la sentencia del TC sobre el Estatuto de Cataluña, hasta el punto de que ha pasado a ser asumida en buena parte de la literatura de diverso género que la ha acompañado como «la sentencia» ${ }^{4}$.

Tanto es así que hemos dado en asumir que «la sentencia» es la STC 31/2010, de 28 de junio, la misma que resuelve el recurso directo de inconstitucionalidad interpuesto por más de 50 diputados (del Grupo Parlamentario Popular) en el Congreso (recurso

2 Vid. Aragón ReYes, Manuel: «¿Estado jurisprudencial autonómico?», RVAP, $\mathrm{N}^{\circ}$ monográfico sobre el Estado Autonómico, 1987.

3 Vid. Balaguer Callejon, Francisco: Las Fuentes del Derecho, Tecnos, Madrid 1991-1992.

4 Vid. La STC 31/2010 sobre el Estatuto de Cataluña ha sido objeto de un extenso debate doctrinal. Por todos, acúdase al número monográfico El Cronista del Estado Social y Democrático de Derecho, ISSN 1889-0016, Nº 
8045/2006). Dato significativo, si se tiene en cuenta que el EA Cat fue objeto de una llamativa avalancha de recursos directos presentados por otros tantos actores legitimados: recurso presentado por el Gobierno de la C.A de La Rioja (9330/2006); recurso presentado por el Gobierno de Baleares (9568/2006): recurso presentado por el Gobierno de Murcia (8829/2006); recurso presentado por el Gobierno de la Comunidad Autónoma de Valencia (9501/2006); recurso presentado por el Gobierno de Aragón (9491/2006), y recurso presentado por el Defensor del Pueblo (8675/2006), fallado este en STC de 16 de diciembre de 2010.

Circunstancias y contenido han determinado de consuno esta hipertrofia de problematicidad subyacente al tortuoso camino que conduce a la sentencia ${ }^{5}$. Las circunstancias las explicaremos en un apartado ulterior. Los contenidos que estructuran los ingredientes básicos de la sentencia los anticipamos ahora como sigue: 1. Cuestiones simbólicas, identitarias y lingüísticas. 2. Cuestiones institucionales. 3. Cuestiones competenciales (relacionadas grosso modo con el par bases/desarrollo), con particular atención a las competencias relativas a la materia de Justicia y Administración de Justicia. 4. Cuestiones financieras.

En cuanto al fallo, la sentencia concentra sus pronunciamientos de inconstitucionalidad en un reducido elenco de objetos: la cláusula de "preferencia» en el uso del catalán como lengua privativa de la C.A de Cataluña; el carácter vinculante de determinados dictámenes del Consejo de Garantías Estatutarias; la exclusión del Defensor del Pueblo en la supervisión de la Administración autonómica y la competencia normativa autonómica de desarrollo de las bases del Estado; la competencia para regular determi-

15, 2010, titulado El Tribunal Constitucional y el Estatut. En él se contienen las siguientes contribuciones: ALBerti Rovira, E.: «El Estado de las Autonomías después de la Sentencia del Tribunal Constitucional sobre el Estatuto de Cataluña», Págs. 90-97; BALAguer Callejon, Francisco: «Las cuestiones institucionales en la STC 31/2010, de 28 de junio», Págs. 62-69; Carrillo Lopez, M.: «Después de la Sentencia, un Estatuto desactivado», Págs. 26-37; De Esteban Alonso, J.: «Reflexiones en torno al voto particular de Javier Delgado», Págs. 12-17; Fernandez Farreres, G. J. «Las competencias de Cataluña tras la Sentencia del Tribunal Constitucional sobre el Estatut», Págs. 38-49; GARCIA-MONCO, Alfonso M.: «Paisaje después de una sentencia: la penúltima reforma de la financiación autonómica», Págs. 80-89; GArCia RocA, F. J.: «De las competencias en el Estatuto de Cataluña según la STC 31/2010, de 28 de junio: una primera lectura integradora», Págs. 50-61; MuÑoz MaCHado, S.: «Dentro de los términos de la presente Constitución», Págs. 4-11; QuAdra-SALCEDo JaNINI, T.: «El modelo competencial en la STC 31/2010, de 28 de junio», Págs. 70-79; Rebollo PuIG, M.: «Elogio de los jueces», Págs. 98-106; Tornos MAs, Joaquín: «El Estatuto de Autonomía de Cataluña y el Estado Autonómico, tras la Sentencia del Tribunal Constitucional 31/2010», Págs. 18-25.

Vid. Tajadura Tejada, J.: «La reforma del Estatuto de Cataluña: propuesta y límites». Viver I PI-SunYer, C. [et al.]: La reforma de los Estatutos de autonomía: con especial referencia al caso de Cataluña, Madrid, Centro de Estudios Políticos y Constitucionales, 2007. Págs. 57-79.

Vid. Blanco Valdes, R.: «La sentencia de nunca acabar», en: Claves de Razón Práctica, No 207, 2010.

Vid. Carreras Serra, F. de: «Reflexiones sobre la propuesta de nuevo Estatuto de Cataluña», Teoría y Realidad Constitucional, 2005, R.2861, $\mathrm{n}^{\circ}$ 16, $2^{\circ}$ semestre, Págs. 43-82, y « ¿Es constitucional el Estatuto de Cataluña? (El Estado de las Autonomías tras la sentencia del TC)», Claves de Razón Práctica, № 206, 2010.

5 Distinguidos constitucionalistas han tomado parte en el debate público, a menudo confrontando su opinión en artículos periodísticos en medios de comunicación. Así los de los profesores J. Pérez Royo, J. J. Solozábal, J. A. Montilla Martos, F. Balaguer, R. Blanco Valdés, E. Albertí Rovira, C. Viver Pi y Sunyer, J. de Esteban, entre otros., yo mismo contribuí a la polémica con varios artículos de prensa; entre otros: «Tomemos en serio al TC y a la Constitución» publicado en El Pais el 29 abril del 2010. 
nados aspectos de la materia de Justicia, y la competencia autonómica para aprobar tributos locales.

\section{LA SENTENCIA DEL TC SOBRE EL ESTATUTO DE CATALUÑA}

La sentencia es, para empezar, la más extensa y compleja de toda la historia del TC. Más de 800 páginas en su versión impresa se acompañan de cuatro prolijos votos particulares (Magistrados: Rodríguez Arribas, Rodríguez Zapata, Conde Martín de Hijas y Delgado Barrio).

Los contenidos más relevantes de la sentencia se corresponden largamente con los puntos que habían venido recibiendo mayor atención y polémica. De un primer lado, las cuestiones simbólicas, identitarias y lingüísticas. En un segundo bloque, las cuestiones competenciales, destacando en éste dos subconjuntos; uno, el relativo a la administración de la Administración de Justicia; otro, el relativo a la interacción entre las bases del Estado y el desarrollo confiado a la competencia de las CC.AA. Un tercer bloque lo integran las cuestiones económico-financieras. Finalmente, en el residual cajón de sastre se aglomerarían objetos de impugnación de diversa índole y calado.

Vaya por delante que todas y cada una de las lecciones importantes que de una sentencia como ésta cabía esperar sólo podían tener sentido desde la reafirmación de muchos años de doctrina sobre la posición jurídica de los Estatutos de Autonomía en la Constitución, y, yendo más allá, sobre las características básicas de nuestro ordenamiento y sobre las reglas y principios definitorios de nuestro sistema de fuentes del Derecho. Ello comporta recordar que los EE.AA. son «normas institucionales básicas» (art. 147.1 CE) sometidas jerárquicamente a la Constitución, norma suprema y fundamental de la que dimanan las demás fuentes del Derecho (art 9.1 CE). Su contenido incorpora los mínimos indispensables contemplados por la Constitución (art. 147.2 CE), sin perjuicio de otros contenidos que no sean privativos bien de la Constitución, bien de otras leyes (orgánicas, aunque no sólo) a las que la Constitución reserva otras funciones específicas (ej: LOPJ y LOFCA).

\section{LAS CUESTIONES SIMBÓLICAS, IDENTITARIAS Y LINGÜÍSTICAS}

Mucho se ha discutido acerca de la adecuación de las proclamaciones del Preámbulo del EACAT a la Constitución. En su sentencia, el TC ratifica que el Preámbulo carece en sí de «valor normativo», lo que no obsta a su valor jurídico a efectos interpretativos. Guiado por esta percepción del impacto y de sus límites, el TC opta por declarar en el fallo la ausencia de «efectos jurídicos» (quiere decir normativos) a las referencias del Preámbulo «Cataluña como nación» y a la «realidad nacional de Cataluña».

Siendo cierto que otros EE.AA de la llamada «última generación». (por ejemplo. el EA. de Andalucía) contemplan referencias análogas, también lo es que la discusión a propósito de la idea constitucional de «Nación», integrándose en su seno de nacionalidades y regiones, ha bordeado demasiado tiempo y demasiadas veces la dis- 
locación semántica, como si el predicado de la «nacionalidad» fuese en sí incompatible e incluso contradictoria con el sustantivo «Nación». La evidencia sugiere que la ideación de la «nacionalidad», a la que se refiere el artículo 2 de la CE., fue acuñada en el ciclo constituyente como un subterfugio conceptual a la búsqueda del pacto constitucional —en un ejemplo de lo que Carl. Schmitt categorizó en su día como «compromiso apócrifo»- bajo el que acomodar pretensiones identitarias de aspiración y vocación confesadamente nacionales.

La sentencia, lejos de disolver la aporía conceptual, la prorroga, toda vez que reafirma la obviedad del carácter «único» en cuanto que «común e indivisible» de la Nación española, en convivencia, sin embargo, con otras dimensiones prácticas (habitualmente referidas en cuanto que «culturales») del concepto de «Nación», tales como la lingüística, histórica, cultural, sociológica, incluso identitaria.

Con la misma óptica se enfoca el «derecho inalienable al autogobierno», dimanado de la Constitución (afirmando, por lo tanto, que no es un derecho previo a éste). Lo mismo que la declaración de que «los poderes de la Generalitat emanan del Pueblo de Cataluña» (art. 2.4 EACat.): el concepto de Pueblo de Cataluña no se asimila al de Pueblo español, titular (único) de la soberanía (art. 1.2 CE). La referencia del artículo. 5 del EACat. a los «derechos históricos» no tiene tampoco el alcance que la Constitución confiere a los derechos forales en su Disposición Adicional Primera. Lo mismo en lo relativo a la ciudadanía, símbolos nacionales a la relación de bilateralidad, e incluso al catalán como «lengua propia» y «vehicular» (aunque no única) de Cataluña, cláusulas todas estas sujetas a la «interpretación conforme» que efectúa el TC.

De modo que, en materia lingüística, la sentencia reafirma el carácter vehicular (no único ni excluyente) del catalán en convivencia con la cooficialidad del castellano afirmado por la jurisprudencia reiterada del TC desde sus pronunciamientos sobre la «normalización lingüística» (STC 94 y 95/86), revalidado en su STC 337/94 y confirmado recientemente por la jurisprudencia del TS (Sala III, sentencia del 21 de diciembre del 2010).

El contenido principal del pronunciamiento del TC respecto a la lengua cooficial respeta, vaya por delante, la regulación del catalán en el ámbito de la enseñanza, es su calidad de «lengua vehicular»y «preferente», aunque no única. En relación con la lengua de las administraciones catalanas y de sus medios de comunicación de titularidad pública, la sentencia establece que el EACAT no puede imponer el carácter «preferente» del catalán, aún cuando admite que el legislador ordinario (de la política lingüística) si que podrá conferir ese trato "preferente» a cualquiera de las dos lenguas cooficiales para «corregir situaciones históricas de desequilibrio».

Además, en este apartado es importante señalar que la sentencia reconoce con claridad la posibilidad de que en un Estatuto de Autonomía se establezca un catálogo de derechos y deberes específicos de la C.A de referencia, complementarios y sin perjuicio de los que la Constitución reconoce y establece para todos los españoles ${ }^{6}$.

6 Vid. CaAmaño, F.: «Sí, pueden: Declaración de derechos y Estatutos de Autonomía», Revista Española de Derecho Constitucional, 2007, nº. 79, págs. 33-46. 


\section{LOS ASUNTOS INSTITUCIONALES}

Una sucinta referencia a las cuestiones institucionales dilucidadas en la sentencia aconseja distinguir dos objetos de enjuiciamiento. De un lado, los relativos a las relaciones institucionales entre la Generalitat y el Gobierno de la Nación (y/o entre la CA de Cataluña y el Estado); de otro, las relativas al procedimiento de reforma del Estatut y a la convocatoria de consultas populares y referendos de ámbito autonómico.

En el primero de estos subconjuntos, el TC aplica el parámetro de la interpretación conforme en todo aquello en que no resuelve la desestimación de las impugnaciones planteadas. Así, somete a interpretación los arts. 174.3 y 182 EACat (participación autonómica en competencias estatales), el art. 180 (participación en procesos de designación de magistrados del TC y vocales del CGPJ) y el 183 (Comisión Bilateral como «marco general y permanente de relación entre Gobiernos»).

En el segundo, más complejo, el fallo de la sentencia establece la doctrina interpretativa concerniente a los artículos 222.1 y 223.1.i) del EACat. Así, en cuanto al 221.1, dispone de interpretación conforme respecto de lo establecido en el art. 149.1.32 CE y en la LO de desarrollo (LO 2/80, de 10 de enero, reguladora de las distintas modalidades de referéndum). En cuanto al art.223.1.i), el TC construye su interpretación a partir de lo dispuesto en los arts. 92.3 y 152.2. de la CE (previsiones constitucionales sobre convocatoria de referéndum en general y autonómica en particular), además de lo previsto en el art. 62.c) CE (convocatoria por el Rey para referéndum a partir de la autorización del Estado, decisión que compete al Gobierno de la Nación) 7 .

En ambos asuntos, el TC trasluce su voluntad de sostener el tenor literal de los preceptos impugnados para descartar las lecturas literales incompatibles, por serlo, con los correspondientes preceptos de la CE, estableciendo bucles argumentativos cada vez más alambicados e imaginativos para construir así su operatividad futura de conformidad a aquellas mismas premisas constitucionales.

Por lo demás, en el ámbito de las instituciones de autogobierno catalán solo resultan afectados por el fallo, declarando su inconstitucionalidad, dos incisos muy concretos: uno, relativo al carácter «vinculante» para el Parlamento de los dictámenes del Consejo de Garantías Estatutarias relacionados con los derechos estatutarios; y otro, la «exclusividad» de la función supervisora del Sindic de Greuges en relación con la Administración autonómica, entendiendo el TC que deberá compartirla con el Defensor del Pueblo cuando afecte a los derechos constitucionales (no a los estatutarios).

Vid. Dí́zz-PICAZo, L.M.: «De nuevo sobre las declaraciones estatutarias de derechos: respuesta a Francisco Caamaño», Revista Española de Derecho Constitucional, no 81, págs. 63-70.

7 Vid. Quadra-Salcedo y Fernández del Castillo, T.: «Después del referéndum de Cataluña: ¡el Estatuto ha muerto! ¡Viva el Estatuto!», Claves de Razón Práctica, n 164, julio-agosto, págs. 4-12, y «Paisaje después de la batalla. La sentencia del TC sobre el Estatuto de Cataluña», Claves de Razón Práctica, n²06, octubre 2010, págs. 20-30.

Vid. Montilla Martos, J.A.: «Apuntes sobre colaboración y participación en el estado autonómico: a propósito de la propuesta de reforma del Estatuto de Cataluña», en: Revista d'Estudis Autonòmics i Federals, $\mathbf{N}^{\circ}$ 1, págs. 131-161.

Vid. Fernández Rodríguez, T.R: «De la reforma de los Estatutos a la reforma de la Constitución», Foro: Revista de ciencias jurídicas y sociales, $\mathrm{N}^{\circ}$ 5, 2007, págs. 13-28. 


\section{LAS COMPETENCIAS}

Pero es en las competencias donde la sentencia se extiende con mayor profusión ${ }^{8}$.

En concreto, afirma con claridad —en relación con los arts. 110 y 112— que el EACat no puede definir «categorías constitucionales», toda vez que la tipología de las competencias (legislación, ejecución, bases/desarrollo) corresponde definirla a la Constitución y al TC.

Con esta premisa en mente, la sentencia desgrana un amplio recital de interpretaciones conformes a la Constitución, salpicadas sólo de algunas excepciones bajo la forma de otras tantas declaraciones de inconstitucionalidad y nulidad. En concreto, concierne a las referencias a las «normas comunes, criterios y standards mínimos» por las que el Estatut asumía la función de delimitar el ámbito material de las bases del Estado conforme a la jurisprudencia constitucional (de manera constante, a partir de la STC 69/88).

Desde esta perspectiva, se somete a interpretación conforme a casi todos los preceptos impugnados, resultando depurados los relativos a las Cajas de Ahorros, Mutualidades no integradas, Bancas y Seguros, arts. 120.2 y 126.2, toda vez que lo básico no puede ser reducido respecto de su configuración en la CE), así como en lo relativo a las entidades de gestión colectiva de derechos de propiedad intelectual (art.155). En lo demás, la sentencia contiene un prolijo listado de preceptos impugnados y lecturas de conformidad tan invasivas como inspiradas en el principio de constitucionalidad de las opciones del legislador principio de («deferencia al legislador»).

Dicho esto, procede constatar que, de lejos, la materia de justicia regulada en el Titulo III (El Poder Judicial en Cataluña) es la que mayor concentración de impugnaciones de constitucionalidad recibió desde el inicio de la discusión a propósito del Estatut.

Habrá que recordar, ante todo, la histórica doctrina acuñada por el TC en sus STC 56/90 y 62/90, a propósito de la LOPJ (Ley Orgánica del Poder Judicial) y de la LDPJ (Ley de Demarcación y de Planta Judicial) de 1985 y de 1988, respectivamente. En esa jurisprudencia, el TC estableció el criterio — con gran alcance diferenciador entre el Estado autonómico y el Estado federal como arquetipo dogmático— de la unidad de la jurisdicción, la unidad del Poder Judicial y la unidad de Gobierno del PJ (arts. 117 y 122 CE), en modo que la descentralización territorial operada por la activación del Titulo VIII de la CE solo podía afectar a la denominada «Administración de la Administración de Justicia» (arts. 149.1.5 CE) de conformidad al llamado principio dispositivo.

Desde este marco conceptual, el TC procede a examinar las numerosas impugnaciones concernientes grosso modo a la Justicia en Cataluña. Los artículos 95 y 107 del Estatut deben leerse así bajo el tamiz de la reserva de la demarcación y de la planta judicial, operada en primer término en favor de la LOPJ, Ley orgánica, y, por su naturaleza, Ley del Estado.

Se condiciona así cualquier atribución a la C.A de Cataluña en materia de Justicia al contenido de la LOPJ. En concreto, la relevante referencia a la actuación del TS se limita así a la unificación de doctrina (entendida esta como función, y no como un

8 Vid. Garcia Roca, J.: «De las competencias en el Estatuto de Cataluña según la STC 31/2010, de 28 de junio: una primera lectura integradora», El Cronista del Estado Social y Democrático de Derecho, págs. 50-61. 
concreto recurso jurisdiccional). De este modo, los artículos 95 (salvo apartados 5 y 6), 97 y 107 EACat son sometidos al tamiz de la interpretación conforme. Otro tanto se predica del art. 96 (Fiscal Superior de Cataluña).

El Consejo de Justicia de Cataluña es objeto, sin embargo, de una declaración de inconstitucionalidad y nulidad (art 95 apartados 5 y 6), 97, 98.1 y 98.2 (apartados a, b, c, d y e), 98.3 y 101.1 (bien a pesar, curiosamente, de que estos dos últimos preceptos no habían sido impugnados, lo que incorpora una ironía teniendo en cuenta el carácter masivo y rayano en la indiscriminación del recurso de inconstitucionalidad planteado por el grupo parlamentario popular contra la práctica totalidad del Estatut). Se parte aquí de la premisa constitucional de la existencia de un único Órgano de Gobierno de los Jueces, el CGPJ (art. 122 CE), sin perjuicio de la eventual e hipotética existencia de órganos desconcentrados en tanto que no afecten al órgano de gobierno de los jueces ni a la reserva material en favor de la LOPJ.

En cuanto al derecho de los aspirantes a juez a optar por la lengua que prefieran cuando se examinen en Cataluña, será, una vez más, la LOPJ la que deba regularlo (art.101.3 EACat), lo que conduce al TC a la aplicación del criterio de la interpretación conforme.

La misma regla de aplica al deber de conocer el catalán en la Administración de Justicia (art.102.1 EACat) y a la valoración del conocimiento del derecho propio (art.102.3 EACat), así como a las previsiones relativas al personal de la Administración de Justicia, condicionados a la LOPJ, y a la organización (—no la regulación-) de la justicia gratuita (art. 106.1 EACat) junto a los procedimientos de mediación y conciliación en cuanto que mecanismos de autocomposición extrajudicial, siempre que no se extiendan al arbitraje.

\section{LA FINANCIACIÓN}

Hemos anticipado que es en el sector Justicia, en la definición del orden competencial (el par bases/desarrollo), y en la financiación, en donde se residencian los más significativos pronunciamientos de inconstitucionalidad de la sentencia.

En efecto, en el Titulo VI («De la Financiación de la Generalidad») se contienen dos importantes declaraciones de inconstitucionalidad que sobrepasan el esfuerzo de interpretación conforme ejercitado sobre el mismo.

En concreto, el art. 206.3 del Estatut establecía literalmente: «Los recursos financieros de que disponga la Generalitat podrán ajustarse para que el sistema estatal de financiación disponga de recursos financieros suficientes para garantizar la nivelación y la solidaridad a las demás Comunidades Autónomas, con el fin de que los servicios de educación, sanidad y otros servicios sociales esenciales del estado del bienestar prestados por los diferentes gobiernos autonómicos puedan alcanzar niveles similares en el conjunto del Estado, siempre y cuando lleven a cabo un esfuerzo fiscal también similar. En la misma forma y si procede, la Generalitat recibirá recursos de nivelación y solidaridad. Los citados niveles serán fijados por el Estado».

El TC decide la constitucionalidad de la referencia a la limitación de la nivelación de determinados servicios en cuanto identificables con los que el art. 158.1 CE refiere 
como «servicios públicos fundamentales». Expulsa del ordenamiento, sin embargo, la condición incorporada: "siempre y cuando lleven a cabo un esfuerzo fiscal también similar». Y ello porque la determinación de cuál deba ser ese esfuerzo corresponde regularla sólo al Estado de acuerdo con sus leyes específicas (la LOFCA y sus reformas y leyes tributarias sustantivas y complementarias), una vez completadas las actuaciones correspondientes en el marco del sistema multilateral de cooperación financiera y de coordinación de competencias fiscales previsto en el desarrollo del art. $158 \mathrm{CE}$.

Abundando en este reconocimiento, el TC aplica el parámetro de interpretación conforme a los impugnados arts. 206.5 y 210 EACat. En el primero («El Estado garantizará que la aplicación de mecanismos de nivelación no altere en ningún caso la posición de Cataluña en la ordenación de rentas per capita entre CC.AA antes de la nivelación), en modo que esa garantía procede no ante la aplicación de esa nivelación, sino cuando esa aportación obedezca exclusivamente a su participación en esos mecanismos.

En cuanto al art. 210 ( (Comisión Mixta»), la interpretación establece que esa cooperación bilateralizada ni excluye ni limita a los multilaterales, ni tampoco a la que el Estado cumple en el pleno ejercicio de sus competencias propias (art. 157.3 CE).

Finalmente, el TC se aplica al enjuiciamiento de las disposiciones adicionales 3, 8, 9 y 10, incidentes en el régimen de financiación de Cataluña, estableciendo en casi todos los casos la interpretación conforme.

Es, sin embargo, en el articulo 218.2 del Estatut (competencia autonómica en materia de financiación local) donde el TC determina la inconstitucionalidad de la capacidad atribuida por este precepto para «establecer y regular» los tributos propios de las entidades locales, por entenderlo incompatible con la autonomía local (arts 140 y. $141 \mathrm{CE}$ ), contra el núcleo central de la autonomía financiera de los municipios (art. $142 \mathrm{CE}$ ), así como de la reserva de Ley en favor del Estado en materia tributaria (Art. 133 CE), tal como han venido siendo construidos estos principios en la jurisprudencia del TC (STC 214/91 y, desde entonces, por todas, STC 233/99).

\section{ReCAPITUlación DE LOS CONTENIDOS DE LA SENTENCIA}

Vemos cómo, en conclusión, cabe entender que el TC desestima largamente la mayor parte de las impugnaciones planteadas en este primero y principal de los variados recursos de inconstitucionalidad que, con procedencias distintas y alcances concomitantes, se cernieron contra el Estatut de Cataluña.

Haciendo esto, el TC somete a interpretación conforme (doctrina interpretativa) un abultado subconjunto de disposiciones del Estatut.

Finalmente, el fallo encierra un selectivo subgrupo de declaraciones de inconstitucionalidad y, por tanto, nulidad, concernientes a tres objetos materiales: Justicia (en donde se ciernen la mayoría de las inconstitucionalidades detectadas), competencias (cernidas a la interacción de los polos del binomio o par bases/desarrollo) y financiación (por invasión de la autonomía local y de reserva del Estado).

Importa advertir de inmediato que las (relativamente) escasas y selectivas declaraciones de inconstitucionalidad no se apoyan en la incompatibilidad directa o frontal del contenido material del precepto estatutario afectado con el correspondiente de la Con- 
stitución, sino en su inadecuación respecto al sistema de fuentes constitucionalizado, es decir, en su falta de correspondencia respecto de la lectura establecida y afirmada por el propio TC en si jurisprudencia a propósito de la integración del llamado «bloque de la constitucionalidad»?

Porque este «bloque» — recuérdese- no se compone tan solo de Constitución y EE.AA, sino también de otras leyes y normas con fuerza, rango y valor de ley, llamadas por la Constitución, en geometrías variables a cumplir funciones específicas en la integración operativa de un régimen delimitador y regulador de competencias y ámbitos institucionales (notablemente, la LOFCA y la LOPJ, pero también las leyes del art. 150 CE; 150.2 CE y las otras leyes marco y de armonización aun sin estrenar, e, incluso, los Reglamentos parlamentarios, en cuanto se refiere a la observación del procedimiento parlamentario y la formación y expresión de la voluntad legislativa del Estado).

Viene a afirmarse con ello algo de gran importancia: por agitado e intenso que fuera el debate a propósito de la compatibilidad del Estatut de Cataluña y de la CE, lo cierto es que los contenidos materiales del Estatut no extravasan lo constitucionalmente lícito o el margen de opción disponible para el legislador. Tanto es así que los mismos contenidos materiales resistirían el test de constitucionalidad si fuesen establecidos en las leyes del Estado (la LOFCA, LOPJ, las leyes de bases y Tributarias del Estado) cuya función específica las distingue en el sistema constitucional de fuentes por ser el tipo de ley destinado a regular ese específico objeto.

Con todo, estas consideraciones no agotan los comentarios doctrinales con los que contribuir a un debate inacabado en torno a la «conllevancia» de la cuestión catalana en España y sobre a la integración de la diversidad en la unidad y de la especificidad del «hecho diferencial» en un sistema común regido por principios que sean al mismo tiempo indisponibles para las partes y vinculantes para todos ${ }^{10}$.

\section{COMENTARIOS SOBRE EL IMPACTO DE LA SENTENCIA EN LA DOCTRINA CONSTITUCIONAL}

Es tal la afluencia de materiales de debate acerca de la incardinación de Cataluña en España — en especial, a propósito del Estatuto de Cataluña en la $\mathrm{CE}$ - que no es fácil contribuir a su esclarecimiento, no digamos ya a su enriquecimiento. Con las debidas cautelas cabe efectuar aquí algunos señalamientos:

1. Primero, estimo inadecuado haber incorporado al fallo un pronunciamiento explícito, sobre el Preámbulo, que no se corresponde con ninguno de los contenidos legalmente establecidos para la parte dispositiva de una sentencia frente a un recurso directo de inconstitucionalidad (desestimación, interpretación conforme o inconstitucionalidad, art. 39 LOTC).

9 Vid. Rubio Llorente, F.: «El bloque de Constitucionalidad», Revista Española de Derecho Constitucional, $\mathrm{n}^{\circ} 27,1989$.

10 Vid. Lopez Aguilar, J.F.: Estado Autonómico y hechos diferenciales, Centro de Estudios Constitucionales, Madrid, 1998. 
Es cierto que el TC ha venido elaborando su propio abanico de opciones desde su «señorío sobre su jurisdicción» (arts. 1.1 y 4 LOTC): este es el caso de su construcción a propósito de la disociación de un fallo de inconstitucionalidad respecto de su nulidad (para evitar así consecuencias sistémicas inasumibles, a partir de la STC 45/89).

Pero no habíamos visto hasta ahora que el TC llevase al fallo un pronunciamiento que contiene, más que una disposición jurídicamente circunscrita a la declaración o no de su conformidad a un precepto de la Constitución, un mensaje relativo a su entendimiento hermeneutico o una declaración de principios.

Es el caso de su insólito comentario sobre la «realidad nacional de Cataluña» y sobre un supuesto fáctico que, por serlo (su reconocimiento por el Parlamento de Cataluña), difícilmente se sujeta a controversia teórica alguna (puesto que los hechos sucedidos, en el mundo real, no admiten refutación): el Parlamento de Cataluña se pronunció en su día a favor del reconocimiento de la identidad de Cataluña como «Nación». Máxime cuando, como es preceptivo (art.2 CE), esta proclamación no perjudica la de la Nación española en cuanto "patria común indivisible de todos los españoles», sujeto de soberanía por la que es en exclusiva el único poder constituyente, de la que dimana la Constitución y a su través, y a partir de ella, todos los poderes del Estado (art. 1.2 CE).

De hecho, la declaración del Parlamento de Cataluña sólo puede expresar y expresa su propio entendimiento político (democráticamente legitimado) de lo que para ese Parlament significa la referencia a la «nacionalidad» a la que se reconoce el derecho a la autonomía de acuerdo con la propia CE (art.2 CE).

2. Un segundo comentario es el que respecta, obligadamente, a la reafirmación del principio de función constitucional, que coadyuva, junto a los vertebrales principios de jerarquía y competencia, al manejo correcto del bloque de constitucionalidad, cuyos perfiles continúan siendo, a estas alturas, más lábiles y abiertos de lo que cabría esperar después de más de 30 años de jurisprudencia del TC sobre el alcance del art. 28 de la LOTC.

Yendo más lejos, se reafirma asimismo la peculiar complejidad de nuestro sistema de fuentes constitucionalizadas, distintivamente complicado, para el comparatista y para el operador jurídico. La «deconstrucción de la Ley» (en expresión de J. García Roca) es una de las formulaciones teóricas que se han esforzado en dar cuenta de esta descomposición factorial de la ley (y de las «normas con rango, valor y fuerza de ley» (art.28 LOTC), con la que la Constitución ha confiado al TC una tarea adicional a la de dilucidar lo que es compatible o no con la Constitución, no sólo por el contenido de las decisiones adoptadas por el legislador en el margen de disposición constitucionalmente legítimo, sino también en función de la forma y del procedimiento normativo en cada caso elegido para esa decisión.

De ahí que siga siendo, todavía, un objeto recurrente de debate la discusión de hasta qué punto sea aceptable que el legislador estatutario (en cuanto legislador orgánico, por ende, legislador estatal), tenga que conformarse, o subordinarse, a otras modalidades o «vestes» de legislador estatal (judicial o financiero); e incluso, yendo más lejos, cómo es posible sostener que lo que diga un Estatuto sea enjuiciado por el TC como expresión de voluntad de una determinada C.A. y no de todo el Estado, en la medida en que el E.A. de referencia es norma de todo el Estado (y no de una C.A.), adoptada con la mayoría absoluta exigida en el art. 81 CE por las Cortes Generales en cuanto que Ley Orgánica, reforzada, por lo tanto, en su voluntad de obligar. 
3. Un tercer comentario digno de señalamiento es el que se refiere a la inagotable polémica respecto de los caracteres de la interpretación constitucional.

De un lado, cuantitativamente, la mayor parte del masivo recurso interpuesto por más de 50 diputados del PP, es desestimada frontalmente. Sólo un (cuantitativamente) reducido subconjunto de impugnaciones da pie a la más larga sentencia de la historia del TC (más de 800 folios dan cuenta de un subconjunto de «interpretaciones conformes», y de unas cuantas, elegidas, declaraciones de inconstitucionalidad). Pues bien, lejos de apaciguar el debate interpretativo, las interpretaciones conformes - por cuantiosas y sobre todo por polémicas - han reavivado la controversia sobre los límites de la hermenéutica constitucional.

De modo que, de otro lado, cualitativamente, el efecto más notable reside en que aún hoy persista la sensación de que buena parte de interpretaciones conformadas han sido establecidas a costa de hacer decir a los preceptos del EA de Cataluña una cosa distinta a la que literalmente dicen, además de someter en un buen número de casos a la Constitución a la lectura prospectiva de los alcances de un Estatuto (y no, en rigor, al revés: someter el Estatuto a la lectura prospectiva de la Constitución).

4. Finalmente, me permito señalar que en el binomio o par bases/desarrollo (como han argumentado, entre otros, Joaquín García Morillo y Tomás de la Quadra-Salcedo Janini) continúa pivotando el objeto más problemático de la actuación de nuestro sistema de fuentes, tanto desde el punto de vista conceptual o dogmático (el alcance de las «bases») como desde el operativo (la técnica normativa o de actos de ejecución por la que se efectúa la delimitación entre ambos polos del binomio) ${ }^{11}$.

Porque de su complejidad y sofisticación se deriva, en términos prácticos, que nada menos que toda una L.O de Estatuto de Autonomía validada en referéndum popular en el respectivo ámbito territorial de referencia no pueda siquiera dar cuenta en ninguno de sus preceptos de lo que ya ha resultado previamente dilucidado en jurisprudencia constitucional consolidada, a la luz de su inadecuación formal a la reserva «estatal» con respecto de las bases, reserva inmune al alcance de ese legislador estatal par excellence que, sin embargo, es el Estatuto en sí.

5. Un comentario adicional: El TC desestima la inmensa mayoría de las impugnaciones, interpreta otros preceptos y declara inconstitucionales unos pocos, los menos.

No deja de resultar curioso que al menos dos de sus declaraciones selectivas de inconstitucionalidad lo hayan sido por alcance (al amparo del art. 39 LOTC), esto es, por conexión interpretativa con otras declaraciones de inconstitucionalidad, aún cuando no hubieran sido directamente impugnados en el recurso.

Recuérdese, y no es poco, que es la primera vez en que el TC determina la inconstitucionalidad de preceptos contenidos en un estatuto, no digamos ya de un Estatuto de Autonomía aprobado por la vía del art. 151, y su reforma sometida a un referéndum popular de aprobación. No era, huelga advertirlo, la primera vez que enjuiciaba un EA: así,

11 Vid. Garcia Morillo, J.: «La versatilidad de lo básico», en: Revista Administración Pública, $\mathrm{N}^{\circ}$ 139/1996.

Vid. Quadra-SAlCEdo Janini, Tomás de la: «El Tribunal Constitucional en defensa de la Constitución. El mantenimiento del modelo competencial en la STC 31/2010, sobre el Estatuto de Cataluña», en: Revista Española de Derecho Constitucional, N 90, 2010. 
con el primer Estatuto de Castilla y León en el asunto de la disposición sobre el Condado de Treviño (STC 99/86), o en la reforma del E.A de Canarias, en el asunto del sistema electoral (STC 225/97).

Sí es, sin embargo, la primera vez en que en el fallo se contienen declaraciones de inconstitucionalidad. La ocasión no era menor sino de máximo voltaje y envergadura en la historia del orden constitucional instaurado en 1978.

De ahí que proceda adicionar ahora algunos otros comentarios acerca del entorno político institucional de este fallo y de los valoraciones que ha merecido en este plano.

\section{COMENTARIOS ACERCA DEL IMPACTO DE LA SENTENCIA EN EL ENTORNO POLÍTICO-INSTITUCIONAL DEL ESTADO AUTONÓMICO}

En este otro orden de consideraciones, procede anotar lo siguiente:

Esta sentencia ha hecho historia porque ha hecho historia el proceso del que trae causa. La sentencia es, seguramente, la más extensa y problemática de la historia del TC porque otro tanto cabe decir del proceso del que trae causa. La sentencia ha resultado un stress test de credibilidad y prestigio al propio TC — incluso en su pervivencia y proyección de futuro- porque otro tanto cabe decir del proceso del que trae causa.

Me explico.

En primer lugar, desde una perspectiva orgánica, el enjuiciamiento del Estatuto de Cataluña dio lugar a una secuencia de recusaciones truculentas orquestadas para precondicionar (y, tendencialmente, predeterminar) la orientación del fallo a partir de la intervención en la propia composición del TC, y, consiguientemente, en la conformación de la mayoría decisoria del interior del órgano. En el arranque de esa secuencia, la desdichada recusación del Magistrado Perez-Tremps supuso un antes y un después en la historia del TC y en su credibilidad en el sistema político. Por cierto, la recusación - a mi juicio apoyada en alegaciones contradictorias con los méritos de idoneidad que hacen de un profesor un candidato elegible al alto honor que incorpora una plaza en el TC- queda aún más deslegitimada en cuanto se constata que ninguna decisión constitucional de fondo en esta sentencia tiene por objeto la «acción exterior» de Cataluña, asunto sobre el que Pérez-Tremps había publicado un trabajo como tratadista y experto, y cuya invocación sirvió para su apartamiento del caso.

Pero, a partir de ahí, nunca como en este caso habíamos asistido a una alineación tan mecánica de «bloques» de magistrados dentro del TC en función de los intereses políticos y materiales enfrentados sobre el eje de un asunto divisorio.

En segundo lugar, desde un punto de vista material, no puede ignorarse que la intencionalidad política asumible sin más en la propia concepción del recurso directo de inconstitucionalidad (art. 162.1.a) — disponible para una minoría de oposición parlamentaria (50 diputados, en este caso del PP) — debe iluminarse en este caso bajo el foco de su ejercicio groseramente discriminatorio respecto de otros EE.AA con contenidos análogos e incluso literalmente idénticos, por transposición, en el marco de la hornada de los denominados «Estatutos de última generación» impulsados en la VIII Legislatura (2004-2008), con el voto favorable en estos últimos casos (EA de Andalucía, EA de la 
C.A. valenciana, EA de Aragón, EA de Castilla-León y EA de Baleares) del mismo PP que decidió atacar con saña el Estatuto de Cataluña ante el TC.

Desde el punto de vista procedimental, la sentencia resultó finalmente la desembocadura del más tortuoso iter de adjudicación de ponencias, intentos (varias veces frustrados) de concluir con un fallo y otras tantas remisiones a lo largo de casi cuatro años.

Es cierto que no ha sido insólito que el propio TC haya incurrido en dilaciones extraordinarias (llegando a fallar hasta 10 años después de la interposición de la acción correspondiente en su registro de entrada), pero también que el objeto extraordinario que desde todas las ópticas le ocupó en esta ocasión hizo especialmente visible e injustificable tan mortificado desfase entre el tiempo de respuesta y el apremio ejercitado desde el entorno político-institucional, e incluso social, del TC.

Finalmente, el TC emerge de la sentencia muy seriamente dañado. Huelga abundar aquí en la línea del organicismo hermenéutico que se ha esforzado en explicar y dar cuenta del debido respeto, acatamiento y asimilación que la tarea del TC merece en la misma medida que sus resultados concretos en cada uno de sus fallos.

Lo cierto es que nunca antes habíamos visto al TC entrampado y obturado en los vericuetos de su propio paisaje y de su paisanaje. Nunca habíamos visto al TC sometido a tanta presión ambiental y tan ostensiblemente dificultado para gestionarla con un pundonor parejo al de su indeclinable función capitular en el sistema.

Problemas de fondo constitucional (soberanía/autonomía; unidad/diversidad; hechos diferenciales/unitariedad del Estado; sujeto constituyente y nación española/naciones, nacionalidades y regiones en España; pueblos españoles/pueblos de España en España; sistema de fuentes; supuestos económico-financieros de la solidaridad y cohesión territorial en España; autonomía territorial/autonomía local), resultan así empecidos en su correcta comprensión y manejo de futuro por la especificidad extraordinariamente problemática de la composición, funcionamiento y proceso del TC con ocasión de tan histórico fallo.

Una reflexión conclusiva procede ahora, finalmente.

\section{CONCLUSIONES: UN COMENTARIO SOBRE EL TC, SU CRISIS Y PERSPECTIVAS DE FUTURO}

El TC ha estado sometido a presiones sin precedentes y se ha jugado su prestigio en cada envite crucial de este proceso extraordinario.

En el transcurso del debate, expresando al mismo tiempo mis convicciones y mis preocupaciones como constitucionalista, tuve ocasión de afirmar en repetidas ocasiones, tanto oralmente como por escrito, una idea que ahora sintetizo: Al enjuiciar el EACat, el TC afrontaba el penoso y al mismo tiempo ineludible deber de examinar, con todo detalle y con visión de Estado y proyección histórica, un estatuto enorme del que se dijo que nacía «con alma de Constitución y cuerpo de reglamento». 223 artículos y decenas de disposiciones fueron masivamente objeto de una abrasiva impugnación general y multifactorial. Con todo, en cuanto que ley subordinada a la CE, ese estatuto, como cualquier otro, podía, y debía, resistir una operación ordinaria de control jurisdiccional de constitucionalidad por el TC. 
De modo que resultaba sistémicamente aceptable un fallo muy similar al que finalmente acabaría adoptando: desestimación en la mayor parte de los puntos impugnados, doctrina interpretativa y, en otros muchos, anulación selectiva de apenas unos cuantos incisos.

Esto es lo que a la postre ha sucedido, solo que lo ha hecho tan a duras penas, con tal alto coste, después y a través de tal dosis de ruido y furia, que cabía predecir: "Cataluña sobrevivirá a esta sentencia; incluso el Estatut de Cataluña sobrevivirá a esta sentencia; pero es el propio TC el que tendrá dificultades para sobrevivir a esta sentencia».

Me temo que así ha resultado. No hablo del órgano en sí — faltaría más—, sino de su reputación, su credibilidad, su auctoritas. Mucho habrá que trabajar para su restauración.

En efecto el TC está hoy sometido como nunca antes a las lesivas derivas de su «judicialización», (secuencia que he descrito, en mi obra «La aventura democrática» ${ }^{12}$ ). Quiero con ello afirmar que si, a lo largo de la experiencia de estos treinta años de democracia, el orden constitucional se ha construido en buena medida a golpe de sentencias del TC — al punto de que se le ha llamado «Estado jurisprudencial autonómico»—, los últimos años describen una inquietante deriva de pérdida de prestigio y, por consiguiente de credibilidad y auctoritas funcional.

No hace falta explicar por qué esto es tan preocupante. Ahí están las lecciones de historia y la experiencia del Tribunal de Garantías de la II República, pionero de la justicia constitucional en la Europa de entreguerras, que resulta gravemente deteriorado tras su intervención a propósito de la reforma agraria en Cataluña.

A la luz de la importancia que cabe atribuir a la autoridad del TC en el conjunto del sistema y sus actores políticos, debe calibrarse el incalculable coste que acarrea la preocupante secuencia del deterioro del TC de la que muchos analistas han venido condoliéndose en estos últimos años.

A mi juicio, evitar este deterioro exige una conciencia clara de las consecuencias que arriesga la judicialización del TC — esto es, la traslación al TC de las mismas inercias y sesgos propios de la integración y los modos de actuar de los órganos judiciales de la justicia ordinaria-, así como una firme denuncia de la insensata estrategia orientada al asalto de las influencias partidistas y mediáticas al TC, groseramente ostensible a lo largo de los últimos años.

En este marco problemático, el TC ha acabado contagiándose de buena parte de las ineficiencias de la justicia ordinaria (esto es, el Poder Judicial) aún sin pertenecer a ella: lentitud, dilaciones indebidas e inseguridad jurídica (resolución desigual de asuntos análogos).

Es cierto que es la explicación del complejo cuadro sintomático de deterioro del TC concurren causas de diversa índole: orgánicas, procedimentales y hasta estructurales.

Pero, junto a unas y otras, y a los problemas del TC han venido a sumarse otras causas de naturaleza estrictamente política: así ha de valorarse sin ambages la responsabilidad contraída por los actores políticos a la hora de causar la pérdida de prestigio de los magistrados y el órgano.

12 Vid. Lopez Aguilar, J.F.: «La Aventura democrática», Ediciones Península, Madrid 2009. 
Lo lamento. Lamento su instrumentalización político-partidista y su prolongado bloqueo, trasunto de una pérdida de respeto difícilmente reversible a los soportes intangibles del test de resistencia y calidad, que después de más de 30 años, deberían superar los materiales basales de nuestro orden constitucional e incluso de nuestra convivencia.

Lamento el daño y perjuicio severamente infligido al permanente reto y al exigente esfuerzo de integrar la diversidad en la unidad, la libertad del autogobierno y la igualdad entre CCAA y entre los españoles.

Y lamento la inescapable sensación de doble vara de medir que describe el recurso y enjuiciamiento del EACat en contraste con los EEAA de contenidos análogos, notablemente los renovados Estatutos de la Comunidad Valenciana y de Andalucía.

La lectura constitucional de la sentencia se presta, a pesar y por encima de todo lo anterior, a valoraciones alentadoramente positivas, incluso tranquilizadoras, respecto a su contribución a la construcción y desarrollo futuro de nuestro orden constitucional en todo lo relativo al desenvolvimiento y manejo de nuestro Estado autonómico.

La sentencia resuelve en términos sistémicamente aceptables un abultado entramado de problemas. Lo hace oponiendo razonamientos frente a un entorno político-social y mediático crispado, exasperado como pocas veces en la expectación del fallo. Aún discrepando en varios puntos de la argumentación socorrida en sus fundamentos jurídicos, lo cierto es que es muy sobresaliente la disposición del TC a «desarmar» las diatribas, los exagerados estrambotes y las controversias ribeteadas en tonos apocalípticos que precedieron a la sentencia convirtiendo al Estatut en un paisaje de batalla.

Ni la sentencia ni el fallo dan la razón a los recurrentes (y interpusieron un recurso tan masivo como, por serlo, fallido) ni, mucho menos, a los profetas del desastre que amenazaron con la catástrofe y la «ruptura» y «fin» de España si prosperaba el Estatuto o si lo «indultaba» el TC.

Los razonamientos y el fallo merecen, desde ese contraste, meditación sosegada y valoración positiva

Pero esto no basta, ni basta con decir solo esto.

Durante más de 20 años, los constitucionalistas hicimos — hemos hecho- hagiografía del TC y de su doctrina. Contribuimos voluntariamente a su prestigio y crédito. Algunos episodios señeros (la «Guerra de las dos Cortes» de los 90 del siglo pasado, la sentencia constitucional 61/97, sobre la Ley del Suelo, entonces vigente), anunciaban el tránsito a un cambio de ciclo que amenazaba en extender la «italianización» de las instituciones generales españolas, incluso a este bastión largamente intocado, resistente, como la Aldea de Asterix, a la presión ambiental de «sobrecalentamiento», «sobresaturación» e «hipermaceración» de la que venían afectados casi todos los demás órganos constitucionales del Estado.

Cabe concluir que esta sentencia señala, también aquí, un antes y un después. El TC se ha expuesto a la crítica pública, ha destripado su procedimiento decisional y la naturaleza profundamente humana de su locomotora y de sus combustibles, esto es, de las razones y motivaciones de sus decisiones. Muchos de los razonamientos y fundamentos expuestos tanto en el extenso cuerpo de la sentencia como en su fallo, inusualmente complejo, además de, por supuesto, en los cuatro votos particulares que lo acompañan, se 
prestan, y así lo demandan, a una explicación más política (cuando no en clave y lenguaje directamente periodístico) que estrictamente hermenéutica.

El TC se ha situado en una encrucijada crítica. Corresponde a sus miembros trabajar duramente para la recuperación de su crédito y prestigio. También a las fuerzas políticas romper el círculo de hierro en que se ha aherrojado la legitimación de ejercicio que toda institución necesita, y, como pocas, el TC. Las Cortes Generales — los grupos parlamentarios y los partidos- deben renovar a tiempo, respetando los criterios y normas constitucionales (también la duración de i9 años, no de 6 , como ha establecido la reforma acordada en la LOTC! para subvenir al desaguisado de retrasos acumulados a estas alturas).

Estoy seguro de que, si así se hace, la comunidad de los constitucionalistas tendrá renovados bríos e inspiraciones a la hora de represtigiar al TC, una de esas preciadas piezas de arquitectura constitucional que no tienen repuesto.

Sin TC no hay Constitución posible; no hablamos ya de que no haya un futuro para esta Constitución democrática normativa y jurisdiccionada, sino de que no será posible la pervivencia de la idea de Constitución que la sustenta. Es mucho lo que está en juego: la misma Constitución; para un constitucionalista, todo.

\section{TITLE: The Ruling.}

ABSTRACT: The article aims to contribute to the debate on the constitutionality of the Statute of Autonomy for Catalonia in force since late 2006. First, it examines the situation created by the lodgement of a significant number of direct appeals of unconstitutionality, among which stands out the general and massive appeal lodged by more than 50 MPs of the Popular Party in the Congress, who exercised the plea of unconstitutionality that the Spanish Constitution of 1978 confers upon the parliamentary minority in the opposition. Second, the article discusses the main implications of the Constitutional Court's judgment on the aforementioned appeals (STC 31/2010, hereinafter «the judgment») from the standpoint of the constitutional doctrine, as well as from the standpoint of the coherence of this statement with the interpretive case law accumulated over the 30 years of development of the so called "constitutional block». Third, the piece of writing includes some comments on the impact of the decision upon the political and institutional circle around the Constitutional Court, most notably in the current context of arguments around the so called Statutes of Autonomy of «last generation (from 2006, and thereaftee).»

Finally, the author reflects on the impact that the doctrinal argument, raised around the Statute of Autonomy of Catalonia, along with the judgement by the Constitutional Court, might cause on the prestige, reputation and functional authority of the «supreme interpreter» of the Constitution itself (namely, the Constitutional Court). The conclusive paradox is described from the certainty that, although both Catalonia and its Statute of Autonomy could resist and overcome the stress test which would be brought about by the case before the Constitutional Court, there was ground for an even greater concern about the survival of the Constitutional Court's reputation, in order to continue its unique task as the guardian of the constitutional order.

RESUMEN: El artículo tiene por objeto una contribución al debate sobre la constitucionalidad del Estatuto de Autonomía de Cataluña, en vigor desde finales de 2006. En primer término, examina la situación generada por la interposición de un significativo número de recursos directos de inconstitucionalidad, entre los que sobresale la impugnación general y masiva interpuesta por 50 diputados del Partido Popular en el Congreso, en ejercicio de la acción de inconstitucionalidad que la Constitución Española de 1978 confiere a la minoría parlamentaria de oposición. En segundo lugar, el artículo comenta los principales alcances de la sentencia del TC recaída sobre este recurso (STC 31/2010, en adelante «la sentencia») desde el punto de vista de la doctrina constitucional y de la coherencia de este pronunciamiento con la jurisprudencia interpretativa acumulada durante 30 años de tratamiento del llamado «bloque de constitucionalidad». En tercer lugar, se acompañan algunos comentarios sobre el impacto de la sentencia en el entorno político-institucional del TC, muy señalada- 
mente en el contexto actual del debate y desarrollo de los denominados EEAA «de última generación». Finalmente, el autor reflexiona sobre el impacto de la disputa doctrinal suscitada alrededor del EACat y de su enjuiciamiento por el TC sobre el prestigio, reputación y autoridad funcional del propio «intérprete supremo» de la Constitución. La paradoja conclusiva se describe desde la certidumbre de que, si bien tanto Cataluña como el propio EACat podian resistir y superar el stress test que supondría el enjuiciamiento por el TC resultante en «la sentencia», cabía la mayor preocupación en torno a la supervivencia del crédito del propio TC para continuar ejerciendo su irreemplazable labor de garantía en el sistema.

KeY Words: Statute. Constitutional block. Conforming interpretation. Guardian of the Constitution.

Palabras Clave: Estatuto. Bloque constitucional. Interpretación conforme. Guardián de la Constitución.

FECHA DE RECEPCIÓN: 20.12.2010. FECHA DE ACEPTACIÓN: 26.01.2011.

UNED. Teoría y Realidad Constitucional, núm. 27, 2011, pp. 221-238. 